\title{
OPEN Author Correction: Supersonic turbulent flow simulation using a scalable parallel modal discontinuous Galerkin numerical method
}

\author{
Tomas Houba, Arnob Dasgupta $\mathbb{D}^{0}$, Shivasubramanian Gopalakrishnan, Ryan Gosse \& \\ Subrata Roy
}

Correction to: Scientific Reports https://doi.org/10.1038/s41598-019-50546-w, published online 08 October 2019

Two references cited in the body of the Article as Spina et al. 1994 and Schlatter \& Örlü 2012 (section Mach 2.25 Turbulent Boundary Layer Flow) were omitted from the References section.

The papers are listed below as References 1 and 2.

Spina, E. F., Smits, A. J. \& Robinson, S. K. The physics of supersonic turbulent boundary layers. Annual Review of Fluid Mechanics 26(1), 287-319 (1994).

Schlatter, P. \& Örlü, R. Turbulent boundary layers at moderate Reynolds numbers: inflow length and tripping effects. Journal of Fluid Mechanics 710, 5-34 (2012).

(c) () Open Access This article is licensed under a Creative Commons Attribution 4.0 International License, which permits use, sharing, adaptation, distribution and reproduction in any medium or format, as long as you give appropriate credit to the original author(s) and the source, provide a link to the Creative Commons license, and indicate if changes were made. The images or other third party material in this article are included in the article's Creative Commons license, unless indicated otherwise in a credit line to the material. If material is not included in the article's Creative Commons license and your intended use is not permitted by statutory regulation or exceeds the permitted use, you will need to obtain permission directly from the copyright holder. To view a copy of this license, visit http://creativecommons.org/licenses/by/4.0/.

(C) The Author(s) 2020 